\title{
Mineralogical and morphological properties of individual dust particles in ice cores from the Tibetan Plateau
}

\author{
GUANGIIAN WU, ${ }^{1,2 *}$ XUELEI ZHANG, ${ }^{3}$ CHENGLONG ZHANG, ${ }^{4}$ TIANLI XU ${ }^{1,5}$ \\ ${ }^{1}$ Key Laboratory of Tibetan Environment Changes and Land Surface Processes, Institute of Tibetan Plateau Research, \\ Chinese Academy of Sciences, Beijing 100101, China \\ ${ }^{2}$ CAS Center for Excellence in Tibetan Plateau Earth Sciences, Beijing 100101, China \\ ${ }^{3}$ Northeast Institute of Geography and Agroecology, Chinese Academy of Sciences, Changchun 130102, China \\ ${ }^{4}$ Research Center for Eco-Environmental Sciences, Chinese Academy of Sciences, Beijing 100085, China \\ ${ }^{5}$ University of Chinese Academy of Sciences, Beijing 100049, China \\ Correspondence: Guangjian Wu <wugj@itpcas.ac.cn>
}

\begin{abstract}
Using a field emission scanning electron microscope and energy-dispersive X-ray spectrometer (FESEM-EDS), individual insoluble dust particles in ice cores recovered from the northern (Dunde), western (Muztagata) and south-eastern (Palong-Zangbo) Tibetan Plateau were analysed in order to reveal the mineralogical and morphological characteristics of the analogue of long-range transported Asian dust. The results reveal that the dust particles are mainly composed of quartz $(17-36 \%$, number abundance), clay (37-48\%) and feldspar (12-18\%). Illite and chlorite are the dominant clay species, while kaolinite is rarely observed. For the three sites, regional differences in the mineral assemblages are significant, in particular the abundance of quartz, chlorite and muscovite species, reflecting the regional provenance of these dust particles and the climatic regime in their source areas. Oxide ratios in clays indicate different weathering strengths of the particles in their source regions, with a higher $\mathrm{K}_{2} \mathrm{O} /\left(\mathrm{SiO}_{2}+\mathrm{Al}_{2} \mathrm{O}_{3}\right)$ in the western and northern Tibetan Plateau. The individual particles have modes of 1.48 and 1.53 in the aspect ratio and circularity distribution respectively. No significant relationship between aspect ratio and circularity was found. Quartz and feldspar particles have a narrow aspect ratio distribution. Muscovite particles have the coarsest grain size, while chlorite particles have the finest.
\end{abstract}

KEYWORDS: Asian dust, ice core, mineralogy and morphology, SEM-EDS

\section{INTRODUCTION}

The chemical composition, morphology and grain size of individual atmospheric dust particles are key factors in estimating their climatic and environmental effects, such as radiative forcing (e.g. Sokolik and Toon, 1999) and cloud condensation nuclei (e.g. Atkinson and others, 2013). The mineralogy and morphology of dust particles vary greatly and affect their optical characteristics (Mishra and others, 2015). The basic properties of individual dust particles are fundamental to the assessment of their effects on radiative forcing (e.g. single scattering albedo), cloud condensation nuclei and ice nuclei. The shape of an atmospheric dust particle is important for calculating its optical properties and assessing its radiation effect (Formenti and others, 2011 and references therein). Dust deposited on a glacier will change its surface albedo and consequently affect glacier melting (e.g. Warren, 1982), especially in glaciers on the Tibetan Plateau, which are adjacent to the Asian arid regions. The shape and mineralogy of dust particles, as well as concentration are critical to assessing their role in glacier melting, but are not well understood at present and particles are assumed to be spherical for simplicity of modelling in some research (e.g. Yasunari and others, 2011). The scanning/transmission electron microscopy and energy-dispersive X-ray

\footnotetext{
* Present address: Institute of Tibetan Plateau Research, Chinese Academy of Sciences, No. 16 Courtyard, Lincui Road, Chaoyang District, Beijing 100101, China.
}

spectrometer (SEM/TEM-EDS) is a mature and effective technique, which can rapidly provide information about the basic compositional and morphological properties of African (e.g. Kandler and others, 2011) and Asian (Okada and others, 2001; Gao and others, 2007; Jeong, 2008) dust particles.

Asian arid land is one of the major sources of dust in the Northern Hemisphere and is one of the key areas for research on the climatic effects of dust. Asian dust displays marked differences in its chemical (e.g. Wu and others, 2015) and mineralogical properties across regional scales. Insoluble particles in high-alpine snow and ice from the Tibetan Plateau, located adjacent to the Asian arid regions, mainly comprise dust emitted from upwind source regions and are analogues of the mid- and upper-tropospheric Asian dust that can also be transported over large distances to the North Pacific and Greenland (e.g. Biscaye and others, 1997; Wu and others, 2010). The SEM/TEM-EDS analyses of individual dust particles in Antarctica and Greenland ice cores have also been widely used to reconstruct atmospheric circulation and the distribution of potential source regions (Gaudichet and others, 1986; Maggi, 1997; Drab and others, 2002; Donarummo and others, 2003). Until now, there has been much less analysis of the mineralogy and morphology of individual dust particles in high-alpine snow and ice cores on the Tibetan Plateau. In this study, we provide preliminary results of mineralogical identification and morphological characterisation of dust particles in ice cores recovered from different physiographic sites on the 


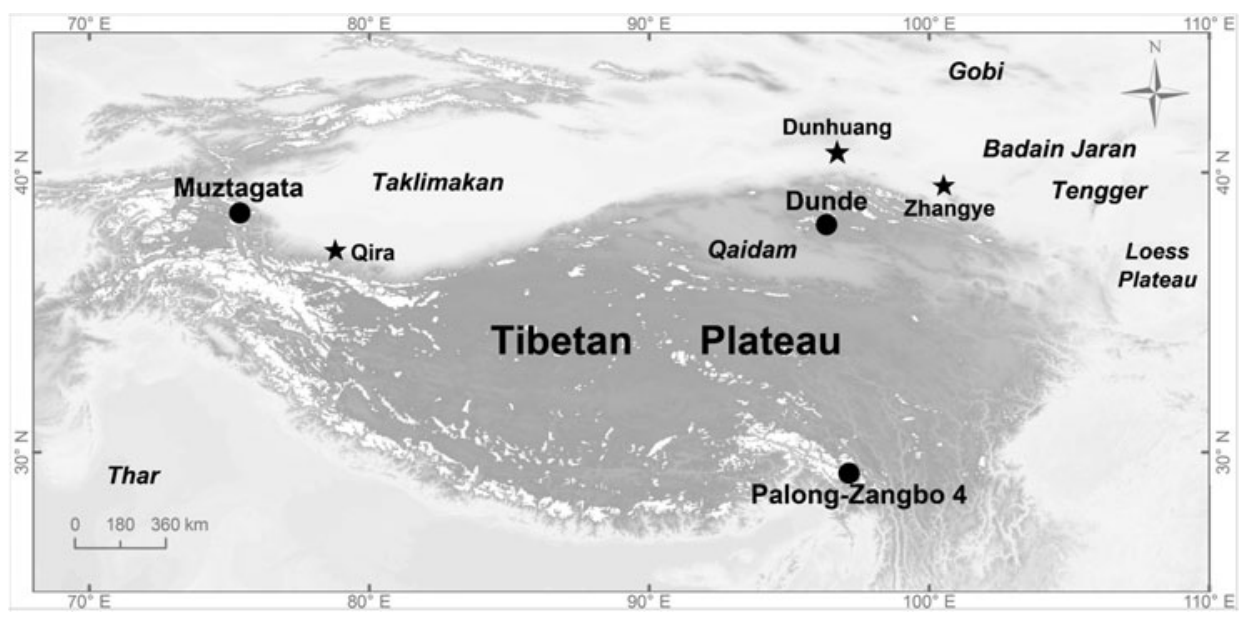

Fig. 1. Map of central Asian deserts and locations of the ice core drilling sites on the Tibetan Plateau.

Tibetan Plateau (Fig. 1), focusing on regional differences in mineralogical composition, dust particle size distribution, shapes obtained from the SEM-EDS and climatic implications.

\section{SAMPLING, EXPERIMENTS AND METHODS}

Three ice core samples from Dunde (northern Tibetan Plateau; $38.10^{\circ} \mathrm{N}, 96.40 .40^{\circ} \mathrm{E} ; 5325 \mathrm{~m}$ a.s.l., $0.04-0.14 \mathrm{~m}$ depth), Muztagata (western Tibetan Plateau; $38.28^{\circ} \mathrm{N}$, $75.01^{\circ} \mathrm{E} ; 6250 \mathrm{~m}$ a.s.l., $30.8-31.8 \mathrm{~m}$ depth) and PalongZangbo No. 4 Glacier (PLZ4, south-eastern Tibetan Plateau; $29.21^{\circ} \mathrm{N}, 96.91^{\circ} \mathrm{E} ; 5502 \mathrm{~m}$ a.s.l., $27.3-28.3 \mathrm{~m}$ in depth) were collected. The Dunde sample contained modern aeolian dust since it was recovered from the uppermost part of the ice core that was drilled in 2002, PLZ4 contained dust (Fig. 2) that is expected to be from 1997 to 1998 based on oxygen isotope dating and the elemental carbon content in the ice core drilled at this site, and the Muztagata sample contained dust from the early 1980 s. The outer part of the ice core slice $(\sim 1 \mathrm{~cm})$ was scraped away using a stainless-steel scalpel in a class 1000 clean cabinet in a cold room $\left(-5{ }^{\circ} \mathrm{C}\right)$. Lyophilisation can preserve some water-soluble minerals (Biscaye and others, 1997), such as calcite, but was not applied in this study due to experimental limitations. The inner sections of the slices were

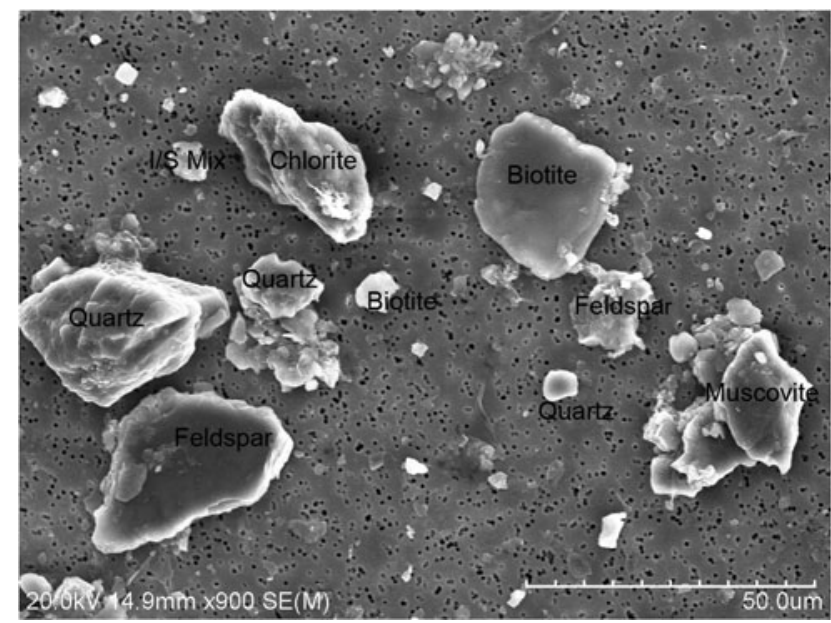

Fig. 2. The SEM image of PLZ4 ice core dust. melted at room temperature and were filtered on a Nuclepore track-etched polycarbonate membrane filter (Whatman Corp.), with a diameter of $47 \mathrm{~mm}$ and pore size of $0.8 \mu \mathrm{m}$, in a class 1000 clean room.

The chemical composition, including element composition and related oxides, and the morphological characteristics of individual particles on part of the Nuclepore filter were analysed using a Hitachi S-4800 field emission SEM equipped with a Horiba EMAX-350 energy dispersive spectrometer at the Analytical and Testing Center, Beijing Normal University (BNU). Randomly selected areas of the filter were photographed at $2000 \times$ magnification. The acceleration voltage, spectrum acquisition time and work distance were set at $20 \mathrm{kV}, 50 \mathrm{~s}$ and $15 \mathrm{~mm}$, respectively. The particles that measured $<1000$ counts $\mathrm{s}^{-1}$ during the EDS analysis were rejected. The number of particles analysed by SEM-EDS from Dunde, Muztagata and PLZ4 were 312, 419 and 257 respectively (see Supplementary Material).

\section{MINERALOGICAL IDENTIFICATION AND MORPHOLOGICAL CHARACTERISATION}

Theoretically, insoluble particles with diameters $>0.8 \mu \mathrm{m}$ were collected and analysed. Previous SEM-EDS studies have set some protocols to semi-quantitatively identify the mineralogy of individual particles. First, we compared element proportions with the known reference minerals, following published procedures (Mudroch and others, 1977; Maggi, 1997; Donarummo and others, 2003). Second, the spectrum pattern of each of the particle was matched manually to that of the 'standard' rock-forming minerals (Severin, 2004). Finally, we compared the oxide composition of each particle with the standard mineral. In this study, each particle was detected by the three (atom ratios, oxide ratios and spectrum-matching) methods described above. This cross-identification can reduce the identification uncertainty and provide a more reliable result than any single method. Clay particles (illite, smectite and kaolinite) were further compared with standard minerals using the ratios $\mathrm{K}_{2} \mathrm{O}$ / $\left(\mathrm{SiO}_{2}+\mathrm{Al}_{2} \mathrm{O}_{3}\right)$ and $\mathrm{SiO}_{2} / \mathrm{Al}_{2} \mathrm{O}_{3}$ (Drab and others, 2002). $\mathrm{A}$ few microorganism fragments with unique morphology (diatoms and pollen) were clearly observed in PLZ4. These fragments may have been transported from the Indian subcontinent or may have come from nearby vegetated land. Fossil fuel combustion products (soot and fly ash) were also 
occasionally observed in PLZ4. These particles are ignored and have been excluded from the mineral identification results in this study because they are non-mineral dust and are small in number. Some results were also rejected due to being non-individual particles (e.g. the overlapping of two adjacent particles).

The SEM/TEM-EDS can only detect an elemental composition of dust particles. This is insufficient to accurately identify the mineral phase because the same elemental composition can form different mineral phases. However, since most of the common minerals have a certain composition, the spectral pattern and element (oxide) ratio by EDS can be a reasonable approach to identifying mineral types of dust particles, assuming each individual particle homogeneously consists of one mineralogical type. Quartz, kaolinite, oxide minerals (e.g. iron oxides) and carbonates are those that can be confidently and easily detected. In practice, the measured spectra pattern and the element (oxide) components are not always exactly identical to the known standards. Furthermore, although the obvious individual particles were chosen for EDS analysis, the mixture cannot be absolutely avoided and might result in a disagreement between EDS results and the standard. In this case, we assume there is a 'dominant' mineral type for those particles. Therefore, this method may have limitations in accurately identifying mineral composition. It is very possible that the identified mineral type is the one that most likely matches the EDS result.

Some researchers argue that in atmospheric models, the combination of some primary mineral types can represent the actual mineralogical dust in the atmosphere in terms of their optical properties. It seems unnecessary to require such an accurate and complex mineral composition in the modelling. The high-resolution mineralogical database of dust-productive soils for atmospheric modelling includes the groups: clay (illite, kaolinite, smectite), calcite, quartz, hematite (includes hematite and goethite), feldspar, gypsum and phosphorus (Nickovic and others, 2012). The clay and silt-sized fractions of global soil units can be characterised in terms of the abundance of 12 minerals (Journet and others, 2014). In the US National Center for Atmospheric Research Community Atmosphere Model, quartz, aluminosilicates, clays, carbonates and iron-bearing minerals are thought to be the primary mineral classes (Albani and others, 2014). Therefore, grouping these particles into suitable types can make mineralogical identification much simpler and realistic. For example, we grouped albite, orthoclase, labradorite, bytownite and anorthite into the feldspar type. The same simplification was applied to all particles from the three sites, thus enabling comparison of regional differences in mineralogical composition. Soluble particles, such as calcite, halite, sylvite and other highly soluble minerals might have dissolved in the meltwater and been lost during filtration, as pointed out in previous studies on Greenland ice core dust (Biscaye and others, 1997; Svensson and others, 2000; Donarummo and others, 2003). Nevertheless, we must point out that transferring the chemical composition to mineralogical data is a challenging task; the classification scheme only reveals the dominant mineralogical type, and other types may be common.

Morphological characterisation of the particles was undertaken manually with Image J software. We measured the longest dimension (a), orthogonal width (b), 2-D area $(A)$ in the SEM image and the perimeter $(\mathrm{L})$ for each particle.
Then several shape parameters were calculated, including the aspect ratio $(A R=a / b)$ and circularity $\left(=L^{2} *(4 \pi A)^{-1}\right)$ parameters. The higher the AR and/or circularity are, the more elongated and irregular the particle is. Here we should point out that the circularity measurement of a given particle is largely dependent on the number of perimeter dots that define its boundary, and therefore it might exhibit relatively greater uncertainty than the AR measurement. A much more accurate measurement can be made when the SEM image of a particle has more pixels. However, since all the measurements were performed in the same way, the two parameters, especially $A R$, are reasonably acceptable and the comparison of the two shape parameters of the particles is valid.

We measured the spherical equivalent diameter (ranging from 1 to $30 \mu \mathrm{m}$ ) of particles in snow and ice core samples using a Coulter Counter (e.g. Wu and others, 2009), which is different to the 2-D area equivalent diameter using a SEM. Here, we suppose the dust particle has the length (a), width $(b)$ to height $(h)$ ratio of $8: 5: 2$ in 3 -D, which infers the flake morphology from recent studies conducted using SEM and atomic force microscopy (AFM) (Veghte and others, 2014; Woodward and others, 2015), and took the height of each particle from the following formula, $h=(a)$ $4+2 b / 5) / 2$. Then the $3-\mathrm{D}$ spherical equivalent diameter was calculated. However, only the particles with a diameter $>0.8 \mu \mathrm{m}$ (pore size of the filter) were chosen for shape characterisation. As the purpose was to identify the mineralogical composition, small sized particles were intentionally not chosen, and coarser particles have a greater chance in practice, of being selected for SEM-EDS analysis. This might bias the results to some degree. Therefore, the grain size of the individual particles will be discussed in view of this limitation.

\section{RESULTS AND DISCUSSION}

\subsection{General mineralogical composition}

In this study, the particles identified were categorised into primary mineral groups, including quartz, feldspar, biotite, chlorite (and chlorite/biotite mix), muscovite (and illite/muscovite mix), illite, illite/smectite (I/S) mix, smectite, kaolinite, carbonate, Hi-Fe group, Hi-Ti group and unknown (Table 1). The combining of certain mineral types (e.g. a type of mixed illite/smectite) has been adopted in some previous ice core studies (e.g. Donarummo and others, 2003), and has also been used in this paper. The predominant mineral group in all particles analysed is aluminosilicate. The most common oxide components within the particles are $\mathrm{SiO}_{2}, \mathrm{Al}_{2} \mathrm{O}_{3}$, $\mathrm{Fe}_{2} \mathrm{O}_{3}, \mathrm{~K}_{2} \mathrm{O}$ and $\mathrm{MgO}$. $\mathrm{SiO}_{2}$ is present in almost all the mineral particles, comprising an amount (wt\% in oxides) ranging from $\sim 1$ to $100 \%$ (pure quartz particles) in the oxides.

In all the three sites, quartz, clays (illite, smectite, kaolinite and chlorite), mica (muscovite and biotite) and feldspar are the major mineral types in these particles, and also the minerals that are most significant when considering regional differences. Quartz particles, which are entirely or predominantly $\mathrm{SiO}_{2}$, constitute the highest particle number abundance of all the mineralogical species, varying from $18 \%$ (Dunde) to $36 \%$ (PLZ4). Clay groups also have a high relative abundance (48\% for Dunde, 39\% for Muztagata, 37\% for PLZ4). Illite and I/S mix are the most abundant clay species and comprise $\sim 23 \%$ of total particles at the three sites. Kaolinite, though it 
Table 1. Particle number abundance (\%) of mineral groups in ice core samples from the Tibetan Plateau and comparison with other results

\begin{tabular}{|c|c|c|c|c|c|c|c|}
\hline Series & Type & Dunde & Muztagata & PLZ4 & Seoul & ${ }^{\mathrm{a}} \mathrm{GISP} 2$ & ${ }^{b} G R I P$ \\
\hline 1 & Quartz & 17.6 & 27.0 & 35.8 & 24 & 34.1 & 25.20 \\
\hline 2 & Feldspar & 11.9 & 18.4 & 13.2 & 16 & ${ }^{\mathrm{c}} 12.5$ & 11.41 \\
\hline 3 & Biotite & 5.5 & 3.8 & 3.1 & & & \\
\hline 4 & Chlorite and C/B Mix & 16.7 & 18.9 & 5.1 & 1 & 0 & \\
\hline 5 & Muscovite and I/M Mix & 13.5 & 7.2 & 8.6 & 2 & 2.7 & \\
\hline 6 & Illite & 14.1 & 6.2 & 6.6 & 1 & 10.8 & 10.72 \\
\hline 7 & I/S Mix & 12.8 & 10.5 & 22.6 & & 13.2 & \\
\hline 8 & Smectite & 3.2 & 2.6 & 1.6 & & & \\
\hline 9 & Kaolinite & 1.0 & 1.0 & 1.2 & 2 & 2.4 & 8.08 \\
\hline 10 & Carbonate & 1.3 & 1.0 & 0.0 & & & 4.50 \\
\hline 11 & Hi-Fe group & 1.6 & 1.0 & 0.8 & 1 & & \\
\hline 12 & $\mathrm{Hi}$-Ti group & 0.6 & 1.2 & 0.0 & 1 & & \\
\hline \multirow[t]{2}{*}{13} & Unknown & 0.3 & 1.4 & 1.6 & & & \\
\hline & Total particle number & 312 & 419 & 257 & & & \\
\hline
\end{tabular}

GISP, Greenland ice sheet precipitation; GRIP, Greenland ice core project.

Note that due to the different classification of mineral types, data are not always available for each type from these references (Seoul: Jeong, 2008; GRIP: Maggi, 1997; GISP2: Donarummo and others, 2003).

a Holocene dust storm sample.

b Average of samples from last glacial maximum (LGM) to marine isotope stage (MIS) $5 \mathrm{e} 5$.

c Including orthoclase and plagioclase.

is also easily detected, represents the lowest fraction in clays, suggesting that these dust particles have experienced weak weathering in their source regions (deserts adjacent to and/ or windward of the Tibetan Plateau). Feldspar content varies from $12 \%$ (Dunde) to $18 \%$ (Muztagata). At each site, there are still a few particles $(\sim 1 \%)$ that cannot be identified. The existence of carbonates, Fe-rich and Ti-rich particles, though their absolute content is at a low level and their number abundance might be subject to statistical uncertainty, can particularly embody the regional differences in mineralogical composition and the environmental implications for the source.

\subsection{The Fe-rich and Ca-rich particles}

Iron oxides have an important effect on the light-absorbing properties of dust (e.g. Sokolik and Toon, 1999). The SEM-EDS results show that many particles contain iron (calculated as $\mathrm{Fe}_{2} \mathrm{O}_{3}$ ), ranging from 0.2 to $74.4 \%$ (wt \% of $\mathrm{Fe}_{2} \mathrm{O}_{3}$ to total oxides) in Dunde (284 out of 312 particles), from 0.4 to $81.6 \%$ in Muztagata (367 out of 419 particles), from 0.4 to $84.6 \%$ in PLZ4 (193 out of 257 particles). Fe-rich ( $\mathrm{Fe}_{2} \mathrm{O}_{3} \%>$ $45 \%)$ and $\mathrm{Ti}$-rich $\left(\mathrm{TiO}_{2} \%>44 \%\right)$ particles were classified as special types (Table 1), and were also identified in eastern Asian dust aerosol samples in Korea (Jeong, 2008).

The materials from Asian dust source regions (deserts) have high Ca abundance (e.g. Zhang and others, 2003). Asian dust aerosol samples collected at other sites show a high $\mathrm{Ca}$ content in individual particles. The Ca-dominant particles (mainly composed of $\mathrm{CaCO}_{3}$ ) from dust aerosol samples collected in Qira $\left(37.00^{\circ} \mathrm{N}, 80.73^{\circ} \mathrm{E}\right.$; southern edge of the Taklimakan) have a numerical frequency of $\sim 3 \%$ (Okada and Kai, 2004), while they comprise 12.5\% (Trochkine and others, 2003) and 7.8\% (Okada and others, $1995)$ in Dunhuang $\left(40.15^{\circ} \mathrm{N}, 94.70^{\circ} \mathrm{E}\right)$ and Zhangye $\left(39.19^{\circ} \mathrm{N}, 100.48^{\circ} \mathrm{E}\right)$, respectively. Dust aerosols collected in Seoul (Korea), which is relatively far from the Asian arid regions, have a number abundance of $7 \%$ for calcite (Jeong, 2008). After long-range transport, the Ca content in
Asian dust aerosols collected in the North Pacific decreases to $<1.5 \%$, even when combined with sulphate (Gao and others, 2007), due to heterogeneous phase reactions (Krueger and others, 2004) or precipitation scavenging and dissolution of Ca-hosting minerals (Ma and others, 2004) during transport.

Among the particles analysed here, $\mathrm{CaO}$ is less commonly detected or has a lower content than other major elements, indicating there is less insoluble calcium in ice cores on the Tibetan Plateau. Although dust in the Dunde ice core is mainly derived from the Taklimakan Desert $\mathrm{(Wu}$ and others, 2010), which contains extensive calcareous deposits (Zhang and others, 2003), calcium-rich particles have a low abundance (1.3\%). We suggest that some water-soluble Cacontaining particles (such as calcite) dissolve during melting (melting occurs under room temperature and lasts for up to $10 \mathrm{~h})$ and are lost during filtration, reducing their reported percentage. The element composition of the insoluble dust fraction (particles) by inductively coupled plasma-mass spectrometer from the three ice cores reveals that the $\mathrm{Ca} / \mathrm{Al}$ ratio (0.27 in Dunde, $n=16 ; 0.20$ in Muztagata, $n=8 ; 0.36$ in PLZ4, $n=38$ ) (Wu and others, 2015) is lower than the upper continental crust average (0.37; Taylor and McLennan, 1995), supporting the above assumption concerning this dissolution. The depletion of $\mathrm{Ca}$ in ice core dust particles suggest that some Ca might be scavenged during dust transport and/or dissolved during melting, which contributes to the very low abundance of calcite in dust from high-alpine snow. Therefore, mineralogical identification of these dissolvable types (e.g. sea salt, halite, calcite) in ice core samples might be limited.

\subsection{Regional differences in the mineralogical composition of dust: implications for provenance and weathering}

The Asian arid regions can be divided into several major areas of dust emission, whose dust properties show significant variation due to their different ultimate origins and 
climatic regimes. The Dunde Ice Cap is located in the centre of the East Asian dust source areas, with Taklimakan and Qaidam as the major provenance areas ( $\mathrm{Wu}$ and others, 2010), while Muztagata is in the western Tibetan Plateau where the Westerlies prevail, and where dust mainly comes from West Asian arid regions (Wu and others, 2015). PLZ4 is located on the south-eastern Tibetan Plateau, where the controlling influence is the southern branch of the high-level Westerlies and the Indian monsoon. Dust in the southern Tibetan Plateau (e.g. Everest) comes from the Thar Desert, the Arabian Peninsula and even the northern Sahara (sub-tropical desert) (Kaspari and others, 2009). Therefore, dust particles in Dunde, Muztagata and PLZ4 may be representative of the mid- and upper-level tropospheric dust from different emission areas of Asian arid regions.

The fundamental cause of differences in mineralogical characteristics is the supply of material from the source. For other types of minerals, such as quartz, chlorite and feldspar, the difference in their abundance is pronounced. Dunde and Muztagata have high chlorite content (16-19\%), while that of PLZ4 is low ( $5 \%)$. Chlorite forms most commonly in soils with moderate leaching, and is preserved in arid and cold environments such as glacial tills (Quigley and Martin, 1963). The variation of chlorite content in the three sites is in accordance with their source region, i.e. temperate deserts (Taklimakan, Qaidam, West Asia) vs sub-tropical deserts (north-western India and the Arabian Peninsula). Muztagata displays the highest feldspar content ( 19\%) of the three sites, indicating that dust over the Pamirs differs from that in the northern and south-eastern Tibetan Plateau. The climate regime of these deserts results in different weathering products and consequently the mineral types of dust particles deposit in the leeward high-alpine snow. Despite the potential uncertainty in mineralogical identification, the difference in mineral composition of dust particles from the three ice cores clearly indicates the spatial variation in the properties of Asian dust.

Compared with the standard clay minerals (Drab and others, 2002), the $\mathrm{K}_{2} \mathrm{O} /\left(\mathrm{SiO}_{2}+\mathrm{Al}_{2} \mathrm{O}_{3}\right)$ ratio vs the $\mathrm{SiO}_{2} /$ $\mathrm{Al}_{2} \mathrm{O}_{3}$ ratio can give clues to the weathering strength of dust material in the source regions (Fig. 3). Compared with the $\mathrm{SiO}_{2} / \mathrm{Al}_{2} \mathrm{O}_{3}$ ratio $(<3.0)$ of standard smectites, the ratios at the three sites are higher, averaging from 3.0 (Muztagata) to 4.5 (PLZ4). The $\mathrm{K}_{2} \mathrm{O} /\left(\mathrm{SiO}_{2}+\mathrm{Al}_{2} \mathrm{O}_{3}\right)$ ratio of illites at the three sites is somewhat higher than that of standard clay minerals and that of Greenland (Summit) (Drab and others, 2002), indicating that Tibetan ice core dust might experience weaker weathering than the standards or weaker sorting than that found in Greenland. A regional difference in this ratio can also be found. The $\mathrm{K}_{2} \mathrm{O} /\left(\mathrm{SiO}_{2}+\mathrm{Al}_{2} \mathrm{O}_{3}\right)$ ratio of illites in PLZ4 ( 0.08) is lower than that of Dunde $(\sim 0.09)$ and Muztagata $(\sim 0.10)$, indicating that aeolian dust particles deposited on the south-eastern Tibetan Plateau have experienced relatively stronger weathering ( $\mathrm{K}$ element depletion) than particles deposited on the northern and western Tibetan Plateau. The significant differences in mineralogical composition of these typical species between the three samples indicate that dust particles were derived from distinct emission areas, and this will enable a much more accurate assessment of the radiative forcing from Asian dust on a regional scale.

\subsection{The quantitative shape parameters of individual particles at different sites}

Almost all the particles have AR and circularity values $<2$, although the maximum for each is 6.72 and 3.62 , respectively. Particles with AR $<2$ account for $80.8 \%$ of the total in Dunde, $90.9 \%$ in Muztagata and $88.3 \%$ in PLZ4, while particles with circularity $<2$ comprise $85.3 \%$ of the total in Dunde, $88.0 \%$ in Muztagata and $90.0 \%$ in PLZ4. We classified both the AR (from the minimum 1.0 to the maximum 6.72 ) and circularity (from the minimum 1.0 to the maximum 3.62 ) values in 30 channels on a logarithmic scale, and found that their distributions obeyed the log-normal law at each site (Fig. 4) and in primary mineral types (Fig. 5). For all 986 particles (312 in Dunde, 417 in Muztagata, 257 in PLZ4) that were characterised for shape, their log-normal modes for AR and circularity were $1.48 \pm 0.22$ and $1.53 \pm 0.21$ respectively. The PLZ4 particles have a lower log-normal mode of circularity (1.37) than Dunde (1.48) and Muztagata (1.62), indicating stronger weathering in the dust source region (tropical deserts). Muztagata particles have the highest circularity mode, and almost no particles have a circularity value $<1.1$. Based on the elemental composition of Muztagata ice core dust, we found that part of the dust was derived from the Pamirs $(\mathrm{Wu}$ and others, 2015). This may in part contribute to the relatively high circularity of Muztagata particles because the weathering strength of these minerals seems not as great as those derived from the deserts.

The 3-D diameter of particles was also calculated assuming the given ratio to the longest dimension and to the orthogonal width. The average mode diameter is $\sim 3.40 \pm 0.78 \mu \mathrm{m}$, which clearly shows that particles in the mid- and uppertroposphere are coarser than previously proposed in the
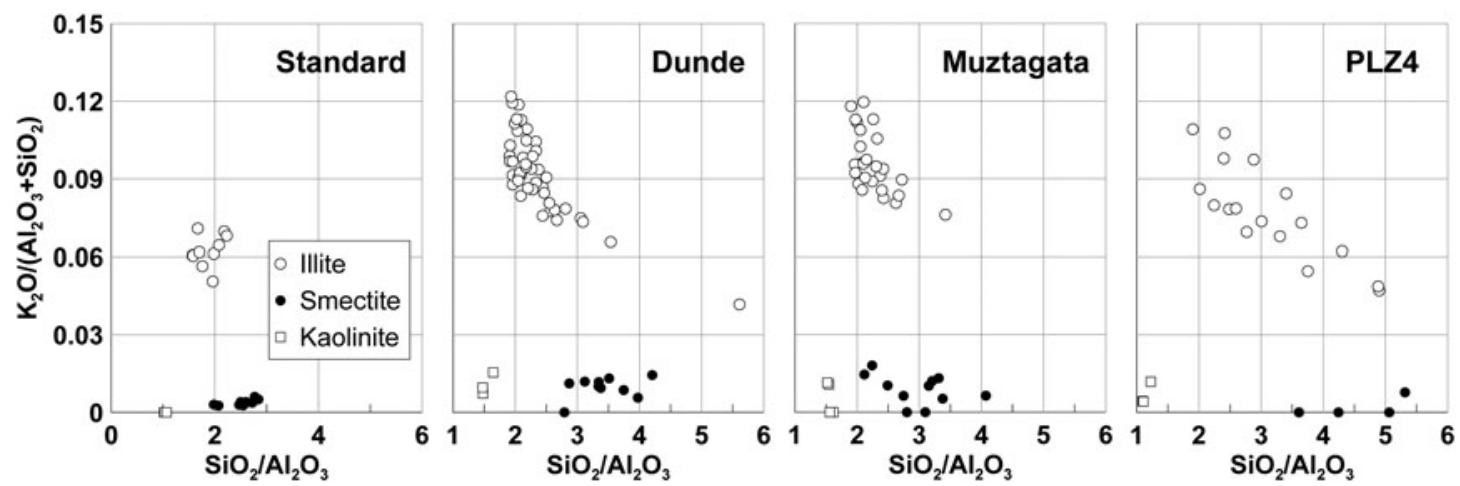

Fig. 3. The oxide ratios of the clays in ice core samples from Dunde, Muztagata and PLZ4, Tibetan Plateau, compared with standard clay minerals (Drab and others, 2002). 

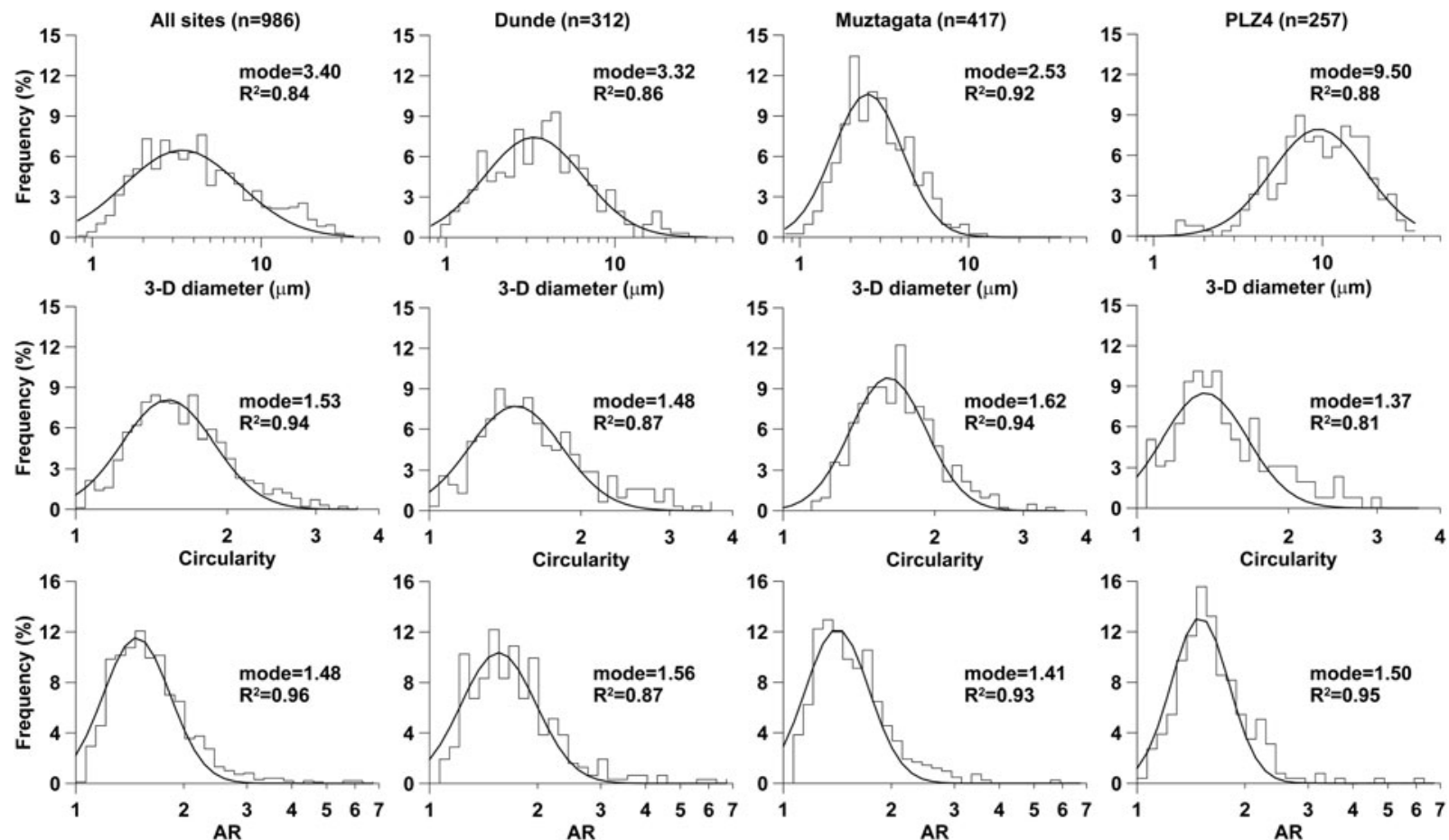

Fig. 4. The shape parameter distribution (on a logarithmic scale) and log-normal fitting results of particles from different sites. Note that the mode, mean and median are the same in the normal/log-normal distribution.

models ( $2 \mu$ m diameter), as we pointed out in our Coulter Counter results (Wu and others, 2009). Dust in Muztagata has the smallest mode diameter, which might be due to the high altitude $(6250 \mathrm{~m}$ a.s.l.). Dust in PLZ4 in the southeastern Tibetan Plateau has the coarsest diameter, due to the local contribution and short transport distance. Our Coulter Counter analysis on the dust from the adjacent Zuoqiupu $\left(29.20^{\circ} \mathrm{N}, 96.90^{\circ} \mathrm{E} ; 5565 \mathrm{~m}\right.$ a.s.l.) ice core also shows a fraction of coarse dust particles.

The quantitative morphological characterisation of Asian dust has been reported in previous studies. The Zhangye and Qira dust aerosol samples show a median AR of 1.381.42 and median circularity of $1.43-1.52$ for mineral particles (Okada and others, 2001; note that in this reference the authors adopted the reciprocal formula to calculate circularity). Both are similar to those in the Tibetan Plateau ice cores. Previous results, as well as ours, indicate that the mid- and upper-tropospheric Asian dust might have similar values of AR and circularity. The AR of Saharan dust particles $(>0.7 \mu \mathrm{m})$ from Cape Verde display median values between 1.6 and 1.7 (Kandler and others, 2011; note that in this reference $A R$ was calculated by $\pi L^{2 *}(4 B)^{-1}$, where $L$ is the longest
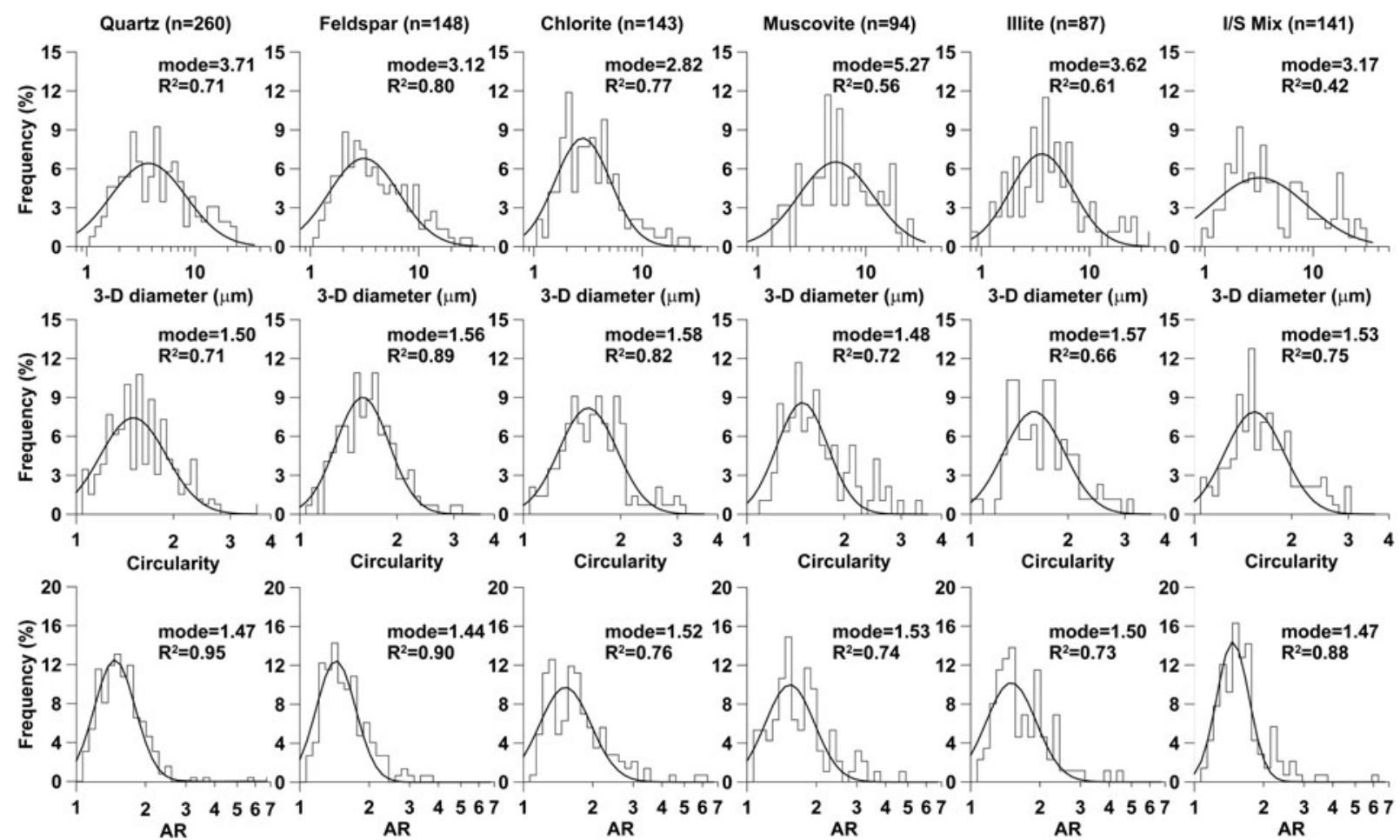

Fig. 5. The shape parameter distribution (on a logarithmic scale) and log-normal fitting results of particles from the primary mineral types. 
projection of the particle outline and B is the area covered by the particle). This might indicate a difference in morphology on the continental scale between Asian and North African dust, the two major dust sources in the Northern Hemisphere.

However, the lowest AR does not accord with the lowest circularity, though it may seem that the lower AR the particle has, the more circular the particle shape should be. Previous research has found that there is no relationship between dust particle AR and circularity for aerosol samples from Qira, Zhangye and Hohhot (Okada and others, 2001). It seems also to be the case for the Sahara (Scheuvens and others, 2011) and India (Mishra and others, 2015) dust aerosols. Our results from ice core samples also indicate there is no significant relationship between AR and circularity either at different sites, or in different types of minerals (not shown). It therefore appears that the two parameters are independent.

\subsection{The shape parameters of some mineral types}

In the following section we discuss the shape of some primary mineral types from the three sites, including quartz, feldspar, chlorite (and C/B mix), muscovite (and I/M mix), illite, I/S mix based on mineralogical identification and shape characterisation. The six primary mineral particles contain $88 \%$ of the total number of particles. The other types will not be discussed because the number of particles is very small.

Among the major mineral types, feldspar and quartz have the lowest AR mode (1.44-1.47), while muscovite and chlorite have the highest (1.53). Quartz has the finest size ranges in log-normal fitting for $\mathrm{AR}\left(R^{2}=0.95\right)$ distribution, and also has a very low circularity value (1.50), suggesting that quartz particles are more regular in shape than other minerals, particularly chlorite. This is a reasonable suggestion because quartz is the most stable rock-forming mineral and the ultimate mineral type for silicate weathering. Illite is coarsest $\left(R^{2}=0.73\right)$ in terms of log-normal fitting in the AR $\left(R^{2}=0.73\right)$ and circularity $\left(R^{2}=0.66\right)$ distributions, while quartz, feldspar and the I/S mix show good fits (Fig. 5), indicating their shape parameters are more concentrated than that of illite. However, some quartz and I/S mix particles are very irregular in shape, with AR values even $>5$. Since quartz can be easily identified and the AR parameter is relatively simple to measure, we are sure that this shape irregularity of some quartz particles occurs naturally.

For circularity distribution, feldspar has the best fitting results $\left(R^{2}=0.89\right)$, while illite has the lowest $\left(R^{2}=0.65\right)$. Chlorite has the greatest circularity value (1.58), while muscovite has the smallest (1.48). Muscovite has a greater 3-D diameter $(5.27 \mu \mathrm{m})$ than other primary types, indicating that this type of particle has the coarsest size. Chlorite has the smallest (2.82 $\mu \mathrm{m})$ grain size. Compared with AR and circularity, the 3-D diameter is less fine (0.42-0.80) in log-normal fitting, suggesting that the particle size has a scattered distribution in shape. It should be pointed out that a small number of these particles for a given mineral type might also contribute to the relatively low coefficient of determination for the log-normal fit.

\section{CONCLUSIONS}

Our SEM-EDS findings provide further detailed information on the mineralogical composition and morphological characteristics of individual dust particles from the Tibetan Plateau ice cores, which improves the control on their optical properties in the modelling. Although the SEM-EDS analysis has some limitations in mineralogical identification, it can adequately provide information on the common types of individual Asian dust particles from ice cores on the Tibetan Plateau, which reflect the mineralogical differences in Asian dust emission regions. Our results indicate that dust particles with a diameter $>0.8 \mu \mathrm{m}$ in high-alpine snow on the Tibetan Plateau are mainly quartz and aluminosilicates. The major mineral types of these dust particles are quartz, clay, mica and feldspar. The PLZ4 dust has higher quartz but lower chlorite abundance than Dunde and Muztagata, showing a significant regional difference in mineralogical composition. However, the illite (including illite and I/S mix) and smectite content of Asian dust appears to be very similar in these different source regions. The $\mathrm{K}_{2} \mathrm{O} /\left(\mathrm{SiO}_{2}+\right.$ $\mathrm{Al}_{2} \mathrm{O}_{3}$ ) ratio and $\mathrm{SiO}_{2} / \mathrm{Al}_{2} \mathrm{O}_{3}$ ratio for clay minerals also indicate differences in weathering strength in the source regions, which is in accordance with modern climate regimes.

The quantitatively characterised parameters of the shape of these types of mineral particles, including aspect ratio and circularity, provide detailed information on the role of dust particles in solar radiation models. The Asian dust from high-alpine snow has AR and circularity modes of 1.48 and 1.53 respectively. There is no significant relationship between AR and circularity, either at the different sites or in different types of minerals, indicating that the two parameters are independent. Muscovite and chlorite have the greatest and finest 3-D diameter, respectively. Our findings also reveal that the various types of mineral particles have different shapes, which should be taken into account in future numerical modelling.

Our results, although still limited by the number of particles analysed and the accuracy of mineralogical identification, provide quantitative mineralogical and morphological characteristics of mid- and upper-troposphere Asian dust, which aids in understanding its radiative impact and glacier melting, with particular regional constraints.

\section{ACKNOWLEDGEMENTS}

We are grateful to Yongliang Li at BNU for completing the SEM-EDS analysis, Daisheng Sun at the Chinese University of Geoscience (Beijing) for helping with mineral identification and Caroline Brimblecombe for improving the text. This work was supported by the National Natural Science Foundation of China (Grant No. 41190083, 41271074, 41203070 and 41205108).

\section{SUPPLEMENTARY MATERIAL}

AUXILIARY.XIs contains the SEM-EDS results (atom and oxide ratio $(\mathrm{wt} \%)$, mineral types, aspect ratio, circularity and a 3-D diameter) of individual particles from Dunde (DD), Muztagata (MA) and PLZ4 ice cores from the Tibetan Plateau. C/B Mix: Chlorite/Biotite Mixture; I/M Mix: Illite/ Muscovite Mixture.

\section{REFERENCES}

Albani S and 8 others (2014) Improved dust representation in the Community Atmosphere Model. J. Adv. Model. Earth Syst., 6 (3), 541-570 (doi: 10.1002/2013MS000279)

Atkinson JD and 8 others (2013) The importance of feldspar for ice nucleation by mineral dust in mixed-phase clouds. Nature, 498, 355-358 (doi: 10.1038/nature12278) 
Biscaye PE and 6 others (1997) Asian provenance of glacial dust (stage 2) in the Greenland Ice Sheet Project 2 Ice Core, Summit, Greenland. J. Geophys. Res., 102(C12), 26765-26781 (doi: 10.1029/97JC01249)

Donarummo J, Ram M and Stoermer EF (2003) Possible deposit of soil dust from the 1930's U.S. dust bowl identified in Greenland ice. Geophys. Res. Lett., 30(6), 1269 (doi: 10.1029/ 2002GL016641)

Drab E, Gaudichet A, Jaffrezo JL and Colin JL (2002) Mineral particles content in recent snow at Summit (Greenland). Atmos. Environ., 36(34), 5363-5376 (doi: 10.1016/S1352-2310(02)00470-3)

Formenti P and 9 others (2011) Recent progress in understanding physical and chemical properties of African and Asian mineral dust. Atmos. Chem. Phys., 11, 8231-8256 (doi: 10.5194/acp11-8231-2011)

Gao Y, Anderson JR and Hua X (2007) Dust characteristics over the North Pacific observed through shipboard measurements during the ACE-Asia experiment. Atmos. Environ., 41(36), 7907-7922 (doi: 10.1016/j.atmosenv.2007.06.060)

Gaudichet A, Petit JR, Lorius C and Lefevre R (1986) An investigation by analytical transmission electron microscopy of individual insoluble microparticles from Antarctic (Dome C) ice core samples. Tellus B, 38(3-4), 250-261 (doi: 10.1111/j.16000889.1986.tb00191.x)

Jeong GY (2008) Bulk and single-particle mineralogy of Asian dust and a comparison with its source soils. J. Geophys. Res., 113, D02208 (doi: 10.1029/2007JD008606)

Journet E, Balkanski Y and Harrison SP (2014) A new data set of soil mineralogy for dust-cycle modeling. Atmos. Chem. Phys., 14, 3801-3816 (doi: 10.5194/acp-14-3801-2014)

Kandler K and 9 others (2011) Electron microscopy of particles collected at Praia, Cape Verde, during the Saharan mineral dust experiment: particle chemistry, shape, mixing state and complex refractive index. Tellus B, 63, 475-496 (doi: 10.1111/j.16000889.2011.00550.x)

Kaspari S and 7 others (2009) A high-resolution record of atmospheric dust composition and variability since A.D. 1650 from a Mount Everest ice core. J. Climate, 22(14), 3910-3925 (doi: 10.1175/2009JCLI2518.1)

Krueger BJ, Grassian VH, Cowin JP and Laskin A (2004) Heterogeneous chemistry of individual mineral dust particles from different dust source regions: the importance of particle mineralogy. Atmos. Environ., 38(36), 6253-6261 (doi: 10.1016/j. atmosenv.2004.07.010)

Ma C-J, Tohno S, Kasahara M and Hayakawa S (2004) The nature of individual solid particles retained in size-resolved raindrops fallen in Asian dust storm event during ACE-Asia. Atmos. Environ., 38 (19), 2951-2964 (doi: 10.1016/j.atmosenv.2004.03.025)

Maggi V (1997) Mineralogy of atmospheric microparticles deposited along the Greenland Ice Core Project ice core. J. Geophys. Res., 102(C12), 18029-18036 (doi: 10.1029/97JC00613)

Mishra SK and 10 others (2015) Morphology of atmospheric particles over semi-arid region (Jaipur, Rajasthan) of India: implications for optical properties. Aerosol Air Quality Res., 15, 974 984 (doi: 10.4209/aaqr.2014.10.0244)

Mudroch A, Zeman AJ and San R (1977) Identification of mineral particles in fine grained lacustrine sediments with transmission electron microscope and $\mathrm{x}$-ray energy dispersive spectroscopy. J. Sedimentol. Petrol., 47(1), 244-250

Nickovic S, Vukovic A, Vujadinovic M, Djurdjevic $V$ and Pejanovic G (2012) High-resolution mineralogical database of dust-productive soils for atmospheric dust modeling. Atmos. Chem. Phys., 12, 845-855 (doi: 10.5194/acp-12-845-2012)
Okada K and Kai K (1995) Features and elemental composition of mineral particles collected in Zhangye, China. J. Meteor. Soc. Japan, 73(5), 947-957

Okada K and Kai K (2004) Atmospheric mineral particles collected at Qira in the Taklamakan Desert, China. Atmos. Environ., 38 (40), 6927-6935 (doi: 10.1016/j.atmosenv.2004.03.078)

Okada K, Heintzenberg J, Kai K and Qin Y (2001) Shape of atmospheric mineral particles collected in three Chinese arid-regions. Ceophys. Res. Lett., 28(16), 3123-3126 (doi: 10.1029/2000GL012798)

Quigley RM and Martin RT (1963) Chloritized weathering products of a New England Glacial Till. Clays Clay Miner., 10(1), 107-116 (doi: 10.1346/CCMN.1961.0100110)

Scheuvens D and 7 others (2011) Individual-particle analysis of airborne dust samples collected over Morocco in 2006 during SAMUM 1. Tellus B, 63, 512-530, (doi: 10.1111/j.16000889.2011.00554.x)

Severin KP (2004) Energy dispersive spectrometry of common rock forming minerals. Kluwer Academic Publishers, Dordrecht

Sokolik IN and Toon OB (1999) Incorporation of mineralogical composition into models of the radiative properties of mineral aerosol from UV to IR wavelengths. J. Geophys. Res., 104(D8), 94239444 (doi: 10.1029/1998JD200048)

Svensson A, Biscaye PE and Grousset FE (2000) Characterization of late glacial continental dust in the Greenland Ice Core Project ice core. J. Geophys. Res., 105(D4), 4637-4656 (doi: 10.1029/ 1999JD901093)

Taylor SR and McLennan SM (1995) The geochemical evolution of the continental crust. Rev. Geophys., 33, 241-265 (doi: 10.1029/ 95RG00262)

Trochkine D and 8 others (2003) Comparison of the chemical composition of mineral particles collected in Dunhuang, China and those collected in the free troposphere over Japan: possible chemical modification during long-range transport. Water Air Soil Pollut., 3(2), 161-172 (doi: 10.1023/A:1023286306728)

Veghte DP and Freedman MA (2014) Facile method for determining the aspect ratios of mineral dust aerosol by electron microscopy. Aerosol Sci. Tech., 48, 715-724 (doi: 10.1080/ 02786826.2014.920484)

Warren SG (1982) Optical properties of snow. Rev. Geophys., 20(1), 67-89 (doi: 10.1029/RG020i001p00067)

Woodward XX, Kostinski A, China S, Mazzoleni C and Cantrell W (2015) Characterization of dust particles' 3D shape and roughness with nanometer resolution. Aerosol Sci. Technol., 49(4), 229-238 (doi: 10.1080/02786826.2015.1017550)

Wu GJ and 5 others (2009) Volume-size distribution of microparticles in ice cores from the Tibetan Plateau. J. Glaciol., 55(193), 859-868 (doi: 10.3189/002214309790152492)

Wu GJ, Zhang CL, Zhang XL, Tian LD and Yao TD (2010) Sr and $\mathrm{Nd}$ isotopic composition of dust in Dunde ice core, Northern China: implications for source tracing and use as an analogue of long-range transported Asian dust. Earth Planet. Sci. Lett., 299(3-4), 409-416 (doi: 10.3189/002214309790152492)

Wu GJ and 5 others (2015) The environmental implications for dust in high-alpine snow and ice cores in Asian mountains. Global Planet. Change, 124, 22-29 (doi: 10.1016/j.gloplacha.2014.11.007)

Yasunari TJ and 7 others (2011) Influence of dust and black carbon on the snow albedo in the NASA Goddard Earth Observing System version 5 land surface model. J. Geophys. Res., 116, D02210 (doi: 10.1029/2010JD014861)

Zhang XY and 9 others (2003) Characterization of soil dust aerosol in China and its transport and distribution during 2001 ACE-Asia: 1. Network observations. J. Geophys. Res., 108(D9), 4261 (doi: 10.1029/2002JD002632) 